\title{
ERBB2 Expression as Potential Risk-Stratification for Early Cystectomy in Patients with pT1 Bladder Cancer and Concomitant Carcinoma in situ
}

\author{
Johannes Breyer ${ }^{a}$ Wolfgang Otto ${ }^{a}$ Ralph M. Wirtz ${ }^{b, c}$ Bernd Wullich ${ }^{d}$ \\ Bastian Keck $^{d}$ Philipp Erben ${ }^{f}$ Maximilian C. Kriegmair ${ }^{f}$ Robert Stoehr ${ }^{e}$ \\ Markus Eckstein ${ }^{\mathrm{e}}$ Mark Laible ${ }^{\mathrm{g}}$ Kornelia Schlombs ${ }^{\mathrm{g}}$ Sebastian Eidt $^{\mathrm{c}}$ \\ Stefan Denzinger ${ }^{\mathrm{a}}$ Maximilian Burger ${ }^{\mathrm{a}}$ Arndt Hartmann $^{\mathrm{e}}$ \\ on behalf of the BRIDGE Consortium
}

\begin{abstract}
${ }^{a}$ Department of Urology, University of Regensburg, Regensburg, ${ }^{b}$ STRATIFYER Molecular Pathology GmbH, and 'Institute of Pathology, St. Elisabeth Hospital Köln-Hohenlind, Cologne, ${ }^{\mathrm{d}}$ Department of Urology, and ${ }^{\mathrm{e}}$ Institute of Pathology, University of Erlangen-Nuremberg, Erlangen, ${ }^{f}$ Department of Urology, University Hospital Mannheim, Mannheim, and ${ }^{\mathrm{g} B i o N T e c h}$ Diagnostics GmbH, Mainz, Germany
\end{abstract}

\section{Key Words}

Bladder cancer - Non-muscle-invasive bladder cancer .

ERBB2 - Carcinoma in situ - Progression - Prognostic factors

\begin{abstract}
Background/Aims/Objectives: It is difficult to identify patients with a non-muscle-invasive bladder cancer (NMIBC) at stage pT1 with concomitant carcinoma in situ (Cis) who will benefit from an early cystectomy. Methods: We retrospectively analyzed clinical data and formalin-fixed paraffin-embedded tissues of patients with NMIBC. Messenger ribonucleic acid (mRNA) expression of progesterone receptor (PGR), estrogen receptor (ESR1), ERBB2, and marker of proliferation Ki-67 (MKI67) was measured by single-step reverse transcription quantitative real-time polymerase chain reaction using RNA-specific TaqMan assays. Relative gene expression was determined by the normalization of 2 reference genes (CALM2, B2M) using the $40 \Delta \Delta C T$ method and relative gene expression was correlated to the histopathological stage and oncological outcome. Results: Of 302 patients with pT1
\end{abstract}

\section{KARGER}

(c) 2016 S. Karger AG, Basel

E-Mail karger@karger.com

www.karger.com/uin
NMIBC in the initial transurethral resection of the bladder, 65 had a concomitant Cis. Elevated ERBB2 expression (>40.1) significantly correlated with progress in patients with and without concomitant Cis ( $p=0.020$ and $p=0.049$, respectively). For the subgroup of pT1 with concomitant Cis, elevated ERBB2 expression significantly discriminated between a highrisk group of $55 \%$ progression-free survival (PFS) and a lowrisk group of $90 \%$ PFS after a 5 -year follow-up $(p=0.020)$. Coxregression analysis revealed ERBB2 expression as the only independent prognosticfactorforPFS $(p=0.0037)$.Conclusions: High mRNA expression of ERBB2 can identify patients with pT1 NMIBC with concomitant Cis, who have a high risk of progression and might benefit from an early cystectomy.

(c) 2016 S. Karger AG, Basel

\section{Introduction}

Bladder cancer is the sixth most common malignancy worldwide in male patients and is in the ninth position in terms of both genders [1]. Approximately $75 \%$ of the pa- 
tients are diagnosed with non-muscle-invasive bladder cancer (NMIBC) [2]. Depending on the stage and grade after transurethral resection, $50-70 \%$ of the patients show disease recurrence and up to $45 \%$ of the tumors progress to more invasive stages [3]. Patients with NMIBC are monitored with cystoscopies over many years. Therefore, molecular markers for stratifying patient treatment and application of novel therapeutic drugs are highly appreciated to elucidate the patients' prognosis.

Currently, NMIBC is stratified into 3 risk groups according to clinical (diameter, focality) and pathological (stage, grade, concomitant carcinoma in situ [Cis]) criteria [2]. This is the basis for treatment decision and followup strategy. The high-risk group contains a subgroup of highest risk tumors. Among others, the stage pT1 bladder cancer with concomitant $\mathrm{Cis}$ is classified as a tumor with the highest risk. In these patients, early radical cystectomy is recommended, if full-dose BCG instillation therapy is refused or if it is not possible to administer the therapy [2]. It has been shown that patients with stage pT1G3 tumors benefit from an early cystectomy [4]. However, while $49 \%$ of patients with stage $\mathrm{pT} 1$ with concomitant $\mathrm{Cis}$ will suffer from progression to muscle-invasive disease [5], half of the patients may be over-treated by radical cystectomy. To date, it is not possible to identify patients in the highest risk group, who will benefit from early cystectomy, which results in a challenging individual treatment decision.

To predict the recurrence and progression of NMIBC, the European Organisation for Research and Treatment of Cancer (EORTC) developed a score (EORTC score) [6]. To improve this limited clinicopathological risk calculator, various molecular markers have been investigated on. Of these, the marker of proliferation Ki-67 (MKI67) has been shown to be associated with the stage and grade in NMIBC [7] and also it has a prognostic impact on NMIBC $[8,9]$.

More recently, molecular inter-tumor heterogeneity has been investigated leading to the identification of distinct molecular classes beyond histopathological classification resembling the molecular features of the luminal and basal breast cancer subtypes with similar differences in the clinical outcome [10-12]. However, most studies have focused primarily on muscle-invasive bladder cancers (MIBCs) or on combined analysis of NMIBC and MIBC. MIBC has been shown to be of mainly basal- and luminal-cell origin, reflecting molecular classification of breast cancer $[10,11]$. Certain parameters such as HER2 expression can be used to distinguish luminal from basal type bladder cancer. The 4 major determinates of the molecular sub-classification in breast cancer are progesterone receptor (PGR), estrogen receptor 1 (ESR1), ERBB2, and MKI67 [10].

ERBB2 Expression as Risk-Stratification for Early Cystectomy
The aim of the present study was to investigate the predictive value of messenger ribonucleic acid (mRNA) expression of the respective markers in the highest risk group of stage pT1 bladder cancer with concomitant Cis compared to stage pT1 without concomitant Cis. To obtain superior sensitivity and objective results, a reverse transcription quantitative real-time polymerase chain reaction (RT-qPCR) assay, which has been established for breast cancer, was used. This subproject focuses on the relevance of ERBB2 mRNA expression, which revealed to be one of the major determinants of luminal bladder cancer.

\section{Patients and Methods}

\section{Study Population}

Overall, 302 patients with stage pT1 NMIBC at initial diagnosis who underwent transurethral resection of the bladder between 1989 and 2009 were included. Patients with concomitant Cis $(\mathrm{pT} 1+\mathrm{Cis})$ as well as patients without concomitant Cis (pT1 - Cis) were enrolled. Transurethral resection was performed supported by photodynamic diagnosis in most cases since the time Hexvix ${ }^{\mathrm{TM}}$ was approved by the FDA and overall, transurethral resection supported by photodynamic diagnosis was performed in about $25 \%$ of the patients. Histopathological parameters of all cases, including grading according to World Health Organization (WHO) 1973 and WHO 2004 classification were assessed by a pathologist specialized in uropathology (A.H.). All specimens contained at least $20 \%$ tumor cells. All patients underwent re-resection and were treated according to an organ-preserving approach.

\section{Isolation of Tumor RNA}

For RNA extraction from formalin-fixed paraffin-embedded (FFPE) tissue, a single $10 \mu \mathrm{m}$ curl was processed according to a commercially available bead-based extraction method (RNXtract ${ }^{\circledR}$ kit; BioNTech Diagnostics GmbH, Mainz, Germany). In brief, a lysis buffer was used to liquefy FFPE tissue slices, while the melting of paraffin was carried out in a thermo-mixer. Tissue lysis was accomplished with a proteinase $\mathrm{K}$ solution. Thereafter, lysates were admixed with germanium-coated magnetic particles in the presence of special buffers, which promote the binding of nucleic acids. Purification was carried out by means of consecutive cycles of mixing, magnetization, centrifugation, and removal of contaminants. RNA was eluated with $100 \mu \mathrm{L}$ elution buffer and RNA eluates were then stored at $-80^{\circ} \mathrm{C}$ until use.

\section{Gene Expression by RT-qPCR}

The MammaTyper ${ }^{\circledR}$ is a molecular in vitro diagnostic tool used in the assessment of the gene expression levels of the 4 cancer biomarkers that are required for the clinical management of breast cancer patients in daily routine clinical practice. Instead of using IHC to assess protein expression of HER2, estrogen receptor $\alpha, P R$, and Ki-67, with MammaTyper ${ }^{\circledR}$, it is possible to measure the mRNA transcripts of the corresponding genes (ERBB2, ESR1, PGR, and MKI67); this was done by using routine FFPE material and by achieving accurate, reproducible, and objective results.

Urol Int 2017;98:282-289 
The mRNA expression levels of ERBB2, ESR1, PGR, and MKI67 as well as of 2 reference genes (REF), namely, B2M and CALM2, were determined by RT-qPCR, which involves reverse transcription of RNA and subsequent amplification of cDNA executed successively as a 1-step reaction. In MammaTyper ${ }^{\circledR}$, the 6 assays (assay $=$ primer pair and probe specific for the respective target sequence) are duplexed into 3 assay mixes, each using a pair of hydrolysis probes labeled with different fluorophores for separately detecting the duplexed assays.

Each patient sample or control was analyzed with each assay mix in triplicates. The experiments were run on a Light Cycler LC480 II (Roche, $\mathrm{CH}$ ) based on the following protocol: $5 \mathrm{~min}$ at $50^{\circ} \mathrm{C}, 20 \mathrm{~s}$ at $95^{\circ} \mathrm{C}$ followed by 40 cycles of $15 \mathrm{~s}$ at $95^{\circ} \mathrm{C}$ and $60 \mathrm{~s}$ at $60^{\circ} \mathrm{C}$ and according to MammaTyper ${ }^{\circledR}$ instructions for use 150528-90020-EU Rev. 3.0.

Forty amplification cycles were applied and the cycle quantification (Cq) threshold values of MKI67 and the 2 REF genes for each sample (S) were estimated as the median of the triplicate measurements. These were then normalized against the mean expression of the REF genes and set off against a calibrator (PC) to correct for inter-run variations $(\Delta \Delta \mathrm{Cq}$ method). The final values were generated by subtracting $\Delta \Delta \mathrm{Cq}$ from the total number of cycles to ensure that normalized gene expression obtained by the test is proportional to the corresponding mRNA expression levels, a method that facilitates the interpretation of data and clinicopathological correlations. The various calculation steps are summarized in the following formula exemplary for MKI67 ( $\mathrm{S}=$ sample, $\mathrm{pc}$ = positive control):

$40-\Delta \Delta \mathrm{Cq}(\mathrm{MKI} 67) \mathrm{S}=40-\{[\mathrm{Cq}(\mathrm{MKI} 67) \mathrm{S}-$ mean $\mathrm{Cq}(\mathrm{REF})$ $\mathrm{S}]-[\mathrm{Cq}(\mathrm{MKI} 67) \mathrm{pc}-$ mean $\mathrm{Cq}(\mathrm{REF}) \mathrm{pc}]\}$

\section{Statistical Methods}

After the exclusion of invalid samples from the total cohort on the basis of predefined criteria, pT1 + Cis and pT1 - Cis samples were analyzed and results of the total cohort were correlated to clinical and pathological parameters. The Spearman product-moment correlation coefficient $r$ was used as a measure of the strength and direction of the linear relationship between variables. Statistical analysis including partitioning testing as well as survival analysis based on Kaplan-Meier and Cox regression analysis was performed with JMP SAS (SAS Institute, Cary, NC, USA) and GraphPad Prism software (version 5.04; GraphPad Software Inc., La Jolla, CA, USA).

\section{Results}

\section{Patient Population}

The total study cohort consisted of 302 NMIBC tumor samples staged pT1 after the central pathological review was completed. Based on predefined criteria, 255 pT1 samples qualified to be analyzed with valid measurements for all 4 biomarkers. In the final cohort of 255 pT1 samples, 65 had a concomitant Cis (pT1 + Cis; Fig. 1). The invalid measurements in 47 samples were due to insufficient RNA input according to prespecified criteria of the

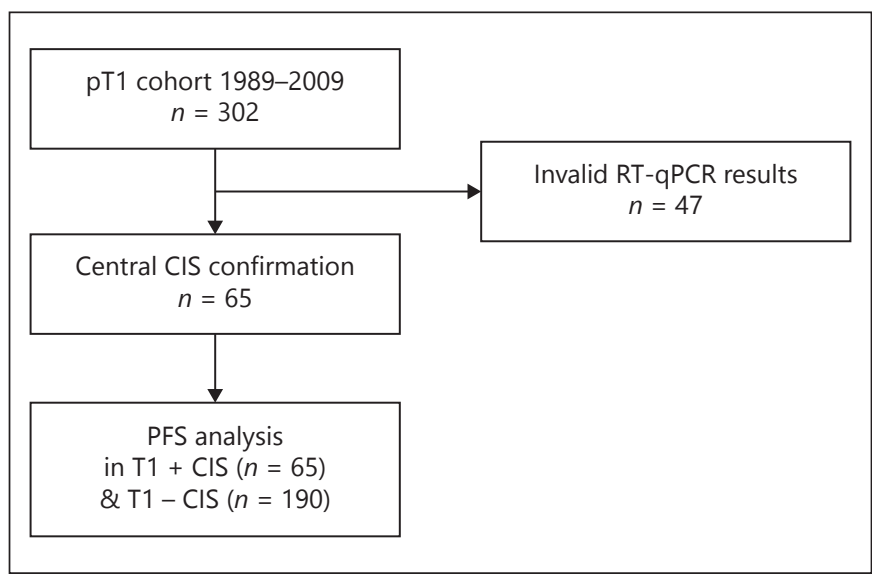

Fig. 1. Remark diagram.

MammaTyper kit and described in the instruction manual of the IVD kit in more detail. In brief, the Cq values of the REF have to be above a minimally required amount of RNA when compared to the synthetic standard quantified in parallel to give a valid sample measurement. Tumor samples were collected from a single institution. The clinicopathological parameters in both cohorts were mostly comparable; only multifocal tumors $(29.2 \% \mathrm{pT} 1+$ Cis vs. $17.4 \%$ pT1 - Cis, $p=0.033$ ) and grade 3 tumors after WHO 1973 classification ( 90.8 vs. $66.3 \%, p<0.001$ ) showed statistically significant differences between the 2 groups (Table 1). The quantitative assessment of ERBB2, ESR1, PGR, and MKI67 mRNA expression resulted in normal distributions with a median expression of 39.95 , $35.28,33.53$, and 37.64 in the Cis cohort and 39.98, 34.42, 32.88 , and 37.53 in the non-Cis cohort after normalization to the housekeeping genes CALM2 and B2M (Fig. 2).

\section{Correlation between Cis and ESR1, PGR, ERBB2, and MKI67 Expression}

ERBB2 mRNA levels were positively correlated to proliferation as determined by MKI67 mRNA quantitation (Spearman rho 0.49; $p<0.0001$ for $\mathrm{pT} 1+$ Cis and Spearman rho $0.27 ; p=0.0002$ for $\mathrm{pT} 1-\mathrm{Cis}$; online suppl. Fig. 1, see www.karger.com/doi/10.1159/000453670). In contrast, mRNA levels of the hormone receptors ESR1 and PGR were not positively associated with proliferative activity but rather negatively associated with MKI67. Importantly, both hormone receptors ESR1 and PGR were positively associated with the presence of Cis (Spearman rho $0.19 ; p=0.0025$ and Spearman rho $0.16 ; p=0.0111$, respectively), whereas there was no association between Cis and ERBB2 or MKI67 mRNA expression. 
Table 1. Characteristics of bladder cancer patients staged pT1 with and without concomitant Cis

\begin{tabular}{|c|c|c|c|c|}
\hline Patient characteristics & $\begin{array}{l}\text { Stage pT } 1-\text { Cis } \\
\text { patients, } n(\%)\end{array}$ & $\begin{array}{l}\text { Stage pT } 1+\text { Cis } \\
\text { patients, } n(\%)\end{array}$ & $p$ value & $\begin{array}{l}\text { Total cohort, } \\
n(\%)\end{array}$ \\
\hline Patient number included & 190 & 65 & & 255 \\
\hline PDD guided TURB & $49(25.8)$ & $15(23.1)$ & 0.399 & $64(25.1)$ \\
\hline Multifocal tumor & $33(17.4)$ & $19(29.2)$ & 0.033 & $52(20.4)$ \\
\hline Tumor size $>3 \mathrm{~cm}$ & $106(55.8)$ & $43(66.2)$ & 0.093 & $149(58.4)$ \\
\hline WHO grading 1973 G3 & $126(66.3)$ & $59(90.8)$ & $<0.001$ & $185(72.5)$ \\
\hline WHO grading $2004 \mathrm{lg}$ & $5(2.6)$ & 0 & & $5(2.0)$ \\
\hline WHO grading 1973 hg & $185(97.4)$ & $65(100)$ & 0.227 & $250(98.0)$ \\
\hline
\end{tabular}

Statistically significant results in bold letters.

Cis, carcinoma in situ; hg, high grade; lg, low grade; PDD, photodynamic diagnostic; TURB, transurethral resection of the bladder; WHO, World Health Organization.

\section{Prognostic Value of ERBB2 Expression}

Intermediate to high ERBB2 mRNA expression $(>40.1)$ was highly significant concerning progression in the pT $1+$ Cis cohort $(p=0.020)$ as well as in the pT1 - Cis cohort $(p=0.049)$. As this cut-off value was close to the median expression of ERBB2 mRNA at $~ 40.0$, subgroups of significant size could be separated into high- and lowrisk groups (Fig. 3b, c). For the pT1 + Cis cohort, high ERBB2 expression significantly discriminated between a high-risk group of 55\% progression-free survival (PFS) after 5-year follow-up and a low-risk group of 90\% PFS after 5-year follow-up.

To further explore the prognostic significance of dichotomization into luminal and basal subtypes by using ERBB2, mRNA Cox regression analysis was performed. ERBB2 remained independently significant for PFS $p=$ 0.0037; Table 2), when adjusting for gender, tumor size, grading, concomitant Cis and focality, while none of the other clinicopathological factors retained significance.

\section{Discussion}

NMIBC still remains a challenging entity for the treating urologist. Until now, stratification of patients into low-, intermediate- and high-risk groups is crucial for further treatment and follow-up. The accepted parameters for classifying NMIBC into these risk groups are pathological staging, grading, number, and diameter of the tumor as outlined in the EAU guidelines [2]. To be able to predict tumor recurrence and progression effectively, the EORTC risk calculator was developed [6].
Here, a concomitant Cis displays the highest single predictive factor for progression, which results in additional 6 points in the risk calculator [6]. This is also recommended in the EAU guidelines, as a pT1 associated with a Cis is subdivided in a subgroup of "highest risk" within the high-risk group [2]. For these patients, an early radical cystectomy should be considered, if intravesical treatment with BCG is refused. Compared to a primary Cis, a concomitant Cis has a worse prognosis $[5,13]$. Griffiths et al. [5] reported a 5-year progression rate of $49 \%$ in patients with pT1 with associated Cis. Only $30 \%$ in this group lived with an intact bladder after 5 years [5]. Patients, who responded to BCG treatment, had a delayed time to progression but without improving the CSS. Thus, the authors of this study do not recommend the intravesical treatment in these highest risk patients [5]. In addition to the pathological features, for T1 with concurrent Cis, no other reliable prognostic markers exist till date.

In this study, we investigated the role of hormone receptor expression of PGR, ESR1, expression of ERBB2 and MKI67, which are all well-established markers in predicting the prognosis of breast cancer and in treatment decision [14]. Spearman's correlation revealed no association between a concurrent $\mathrm{Cis}$ and expression of ERBB2 and MKI67. But there was a significant association between ERBB2 and MKI67 mRNA expression, which can also be found in breast cancer [15].

As described earlier, half of all patients with a pT1 with concomitant Cis will show a progress and only a minority will retain an intact bladder, as early radical cystectomy should be considered [5]. By now, it is not 


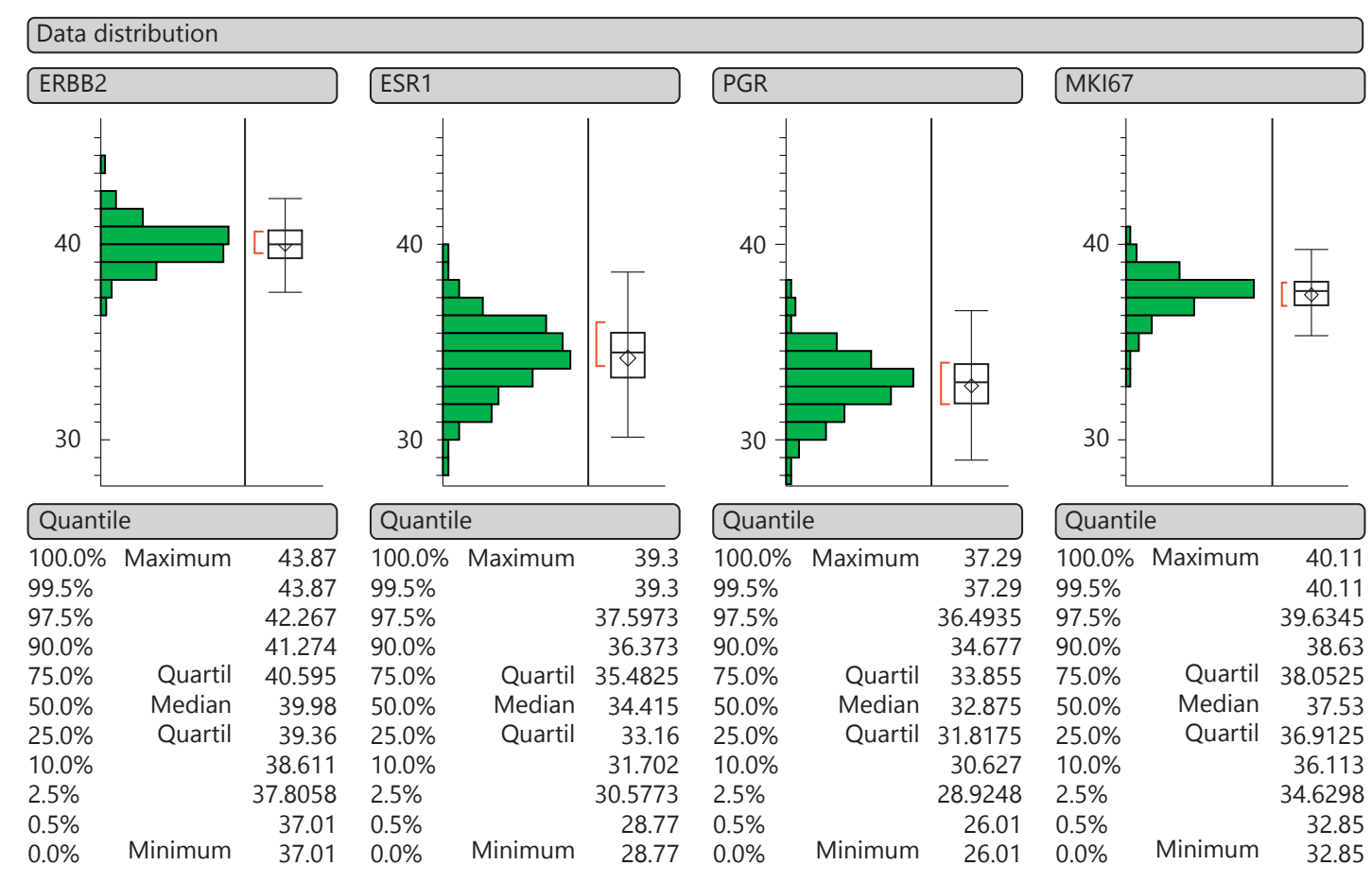

a

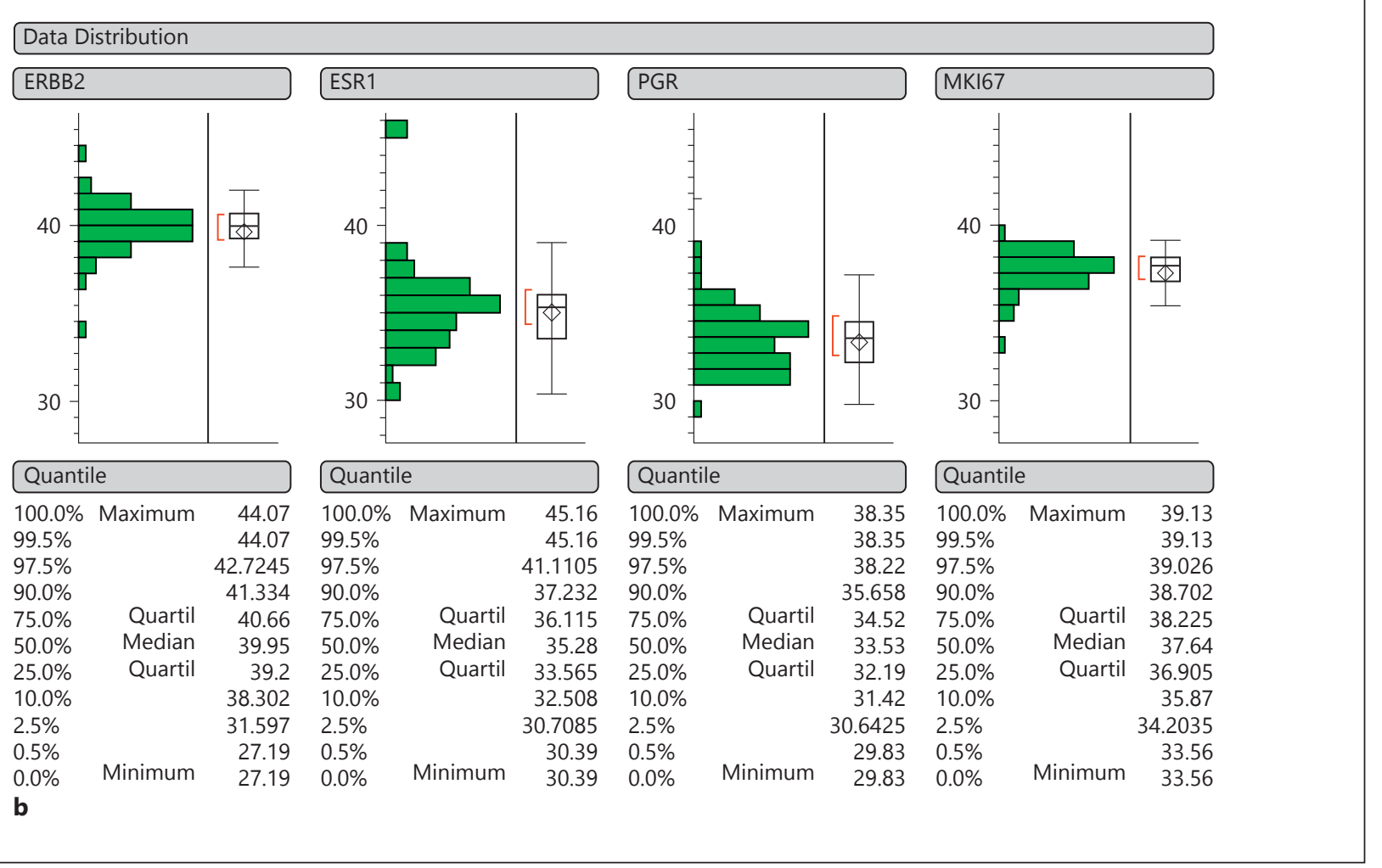

Fig. 2. Data distribution of ERBB2, ESR1, PGR, and MKI67 mRNA levels in the pT1 + Cis cohort (a) and pT1 - Cis cohort (b). 


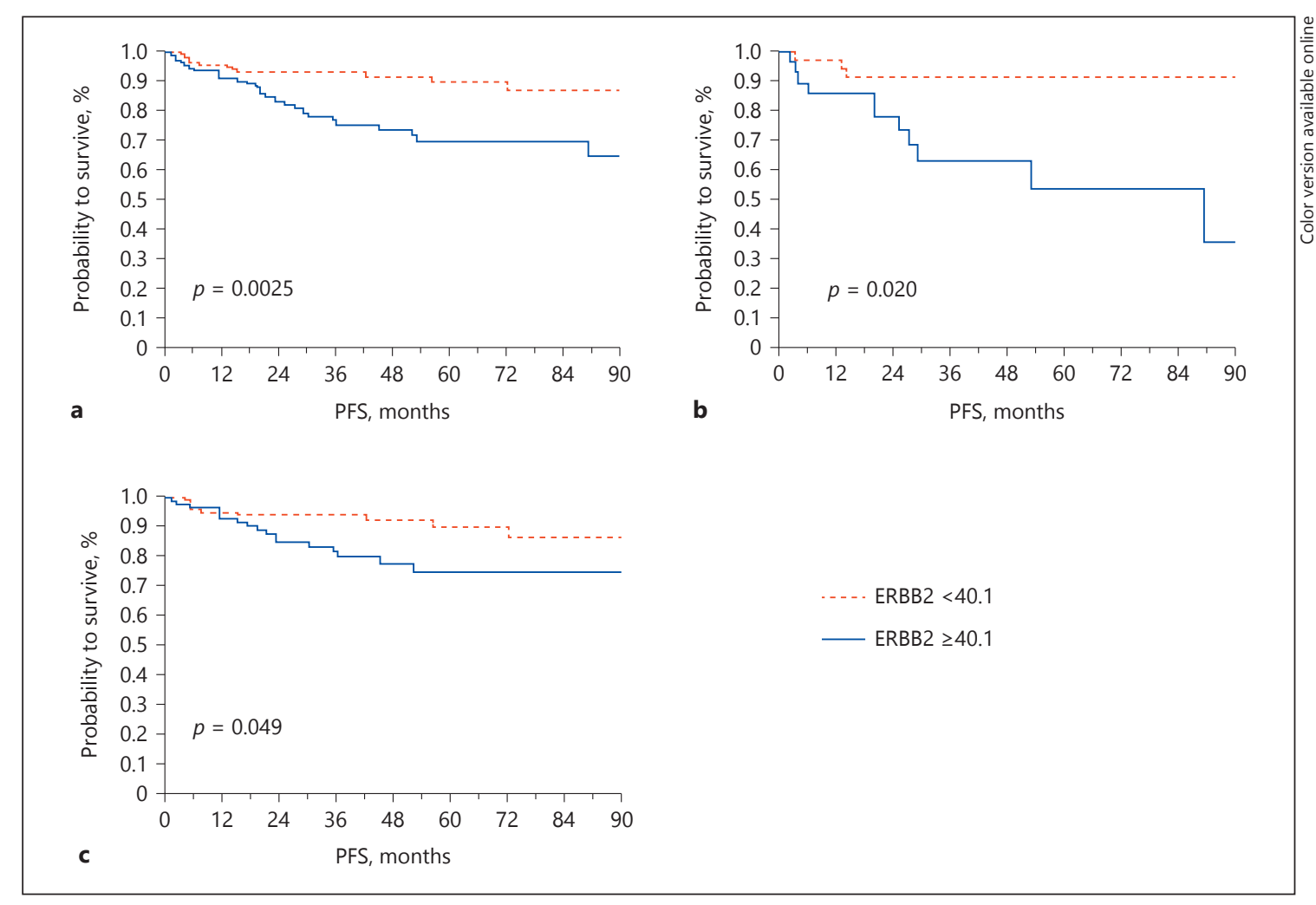

Fig. 3. Kaplan-Meier analysis of PFS in the total cohort (a), pT1 + Cis cohort (b), and pT1 - Cis cohort (c) based on ERBB2 mRNA expression.

possible to identify those who will face difficulties due to progress and will benefit from early radical cystectomy. In terms of molecular markers, high immunohistochemical expression of Ki67 has been associated with high-grade tumors in T1 [16]. Ki67 expression is furthermore associated with survival in pT1 bladder cancer [8] and also in the subgroup of T1G3 tumors [9]. It has been suggested that Ki67 expression be added to the EORTC risk calculator to improve predictive accuracy of recurrence and progression [17]. In this study, we did not find an association with MKI67 expression in the subgroup of $\mathrm{T} 1$ with concomitant Cis. Consequently, it seems not to be suitable for predicting progression in this highest risk group.

In this study, a high expression of ERBB2 could divide the highest-risk group of patients with pT1 and concomitant Cis into a low-risk group with 90\% PFS after 5 years from a high-risk group with 55\% 5-year PFS. Little is known about the expression of ERBB2 in Cis of the bladder. Gunia et al. [18] could show a strong expression of HER2 in Cis, whereas the non-Cis tissue showed a weak to absent HER2 expression in immunohistochemical stain-
Table 2. Multivariate Cox regression analysis of clinic-pathological parameters and ERBB2 mRNA expression $(>40.1)$ in the total cohort for PFS

\begin{tabular}{lll}
\hline & L-R chi & \\
\hline ERBB2 $(\geq 40.1$ vs. $<40.1)$ & 8.44509903 & $\mathbf{0 . 0 0 3 7}$ \\
Gender, female vs. male & 0.2523134300 & 0.6155 \\
Tumor size ( $>3$ vs. $\leq 3$ cm) & 1.64541976 & 0.1996 \\
WHO grading 1973 (G3 vs. G2) & 2.50578913 & 0.1134 \\
Focality (multifocality vs. unifocality) & 0.20922888 & 0.6474 \\
Concomitant Cis (yes vs. no) & 2.36918853 & 0.1238 \\
\hline
\end{tabular}

$p$ values $<0.05$ are indicated in bold.

Cis, carcinoma in situ; WHO, World Health Organization.

ing. Sjödahl et al. [12] could not find an association between ERBB2 expression and the stage and grade of bladder cancer. Chen et al. [19] could show that ERBB2 amplification could only be found in high-grade NMIBC and goes along with a more aggressive behavior and risk for progression. In this study, the researchers stratified only 
for low-risk and high-risk tumors. Furthermore, ERBB2 amplification results in increased ERBB2 mRNA expression in high-grade bladder cancer; this points to a more aggressive behavior of these tumors and this finding is in line with our results [20]. This is underlined by the finding that a strong Her2 expression is found more often in patients with metastatic bladder carcinoma than in those without metastases [21]. In an IHC analysis in pT1G3 NMIBC, HER2 status was not associated with recurrence or progression [22]. The main limitation of IHC-based studies is the lack of standardization and objectiveness. The results for HER2 mRNA expression as well as for the other markers in this study are reproducible and objective and can be easily standardized. Thus, a high HER2 expression may help to identify patients with pT1 and concomitant Cis who will benefit from early cystectomy, as it has been shown in the case of pT1G3 tumors [4].

Furthermore, currently, HER2 also represents a target for a targeted therapy with drugs established in breast cancer. These patients with high expression of HER2 may undergo specific anti-HER2 treatment instead of early cystectomy and instead of BCG therapy. In studies related to bladder cancer cell lines, drugs targeting HER2 showed promising antitumor effects in HER2 overexpressing bladder cancer $[23,24]$. The HER2 antibody trastuzumab has been tested in metastatic bladder cancer $[25,26]$, but to date there is little evidence on the efficacy of this drug.

The major weakness of this study is its retrospective nature with data from a single center. To confirm and verify the results, a validation in a prospective multi-center study will be necessary.

\section{Conclusions}

In this study, we could show that high mRNA expression of ERBB2 can divide the highest risk group pT1 with concomitant Cis into a low-risk group for progression and a high-risk group for progression. This has considerable clinical implications, as patients who will benefit from an early cystectomy might be identified at the time of initial diagnosis. This reproducible and objective method should consequently be evaluated in a prospective multicenter study.

\section{Statement of Ethics}

Informed consent was obtained from all the individual participants included in the study.

\section{Funding}

The work on this topic was funded by the German Cancer Aid (Deutsche Krebshilfe), grant number 110541.

\section{Disclosure Statement}

R.M.W. and S.E. are founders of STRATIFYER Molecular Pathology GmbH. R.M.W. is an employee of STRATIFYER Molecular Pathology GmbH. M.L. and K.S. are employees of BioNTech Diagnostics GmbH.

\section{Acknowledgments}

The authors thank Sefanie Herlein and Elke Veltrup for their excellent technical support.

\section{References}

1 Ferlay J, Soerjomataram I, Dikshit R, Eser S, Mathers C, Rebelo M, Parkin DM, Forman D, Bray F: Cancer incidence and mortality worldwide: sources, methods and major patterns in GLOBOCAN 2012. Int J Cancer 2015; 136:E359-E386.

2 Babjuk M, Böhle A, Burger M, Capoun O, Cohen D, Compérat EM, Hernández V, Kaasinen E, Palou J, Rouprêt M, van Rhijn BW, Shariat SF, Soukup V, Sylvester RJ, Zigeuner R: EAU guidelines on non-muscle-invasive urothelial carcinoma of the bladder: update 2016. Eur Urol 2016;pii:S0302-2838(16)30249-4.

3 Prout GR Jr, Barton BA, Griffin PP, Friedell $\mathrm{GH}$ : Treated history of noninvasive grade 1 transitional cell carcinoma. The National Bladder Cancer Group. J Urol 1992;148: 1413-1419.
4 Denzinger S, Fritsche HM, Otto W, Blana A, Wieland WF, Burger M: Early versus deferred cystectomy for initial high-risk pT1G3 urothelial carcinoma of the bladder: do risk factors define feasibility of bladdersparing approach? Eur Urol 2008;53:146152.

5 Griffiths TR, Charlton M, Neal DE, Powell $\mathrm{PH}$ : Treatment of carcinoma in situ with intravesical bacillus Calmette-Guerin without maintenance. J Urol 2002;167:2408-2412.

6 Sylvester RJ, van der Meijden AP, Oosterlinck W, Witjes JA, Bouffioux C, Denis L, Newling DW, Kurth K: Predicting recurrence and progression in individual patients with stage Ta T1 bladder cancer using EORTC risk tables: a combined analysis of 2596 patients from seven EORTC trials.
Eur Urol 2006;49:466-475; discussion 475477.

7 Limas C, Bigler A, Bair R, Bernhart P, Reddy P: Proliferative activity of urothelial neoplasms: comparison of BrdU incorporation, Ki67 expression, and nucleolar organiser regions. J Clin Pathol 1993;46:159-165.

8 Otto W, Denzinger S, Fritsche HM, Burger M, Rößler W, Bertz S, May M, Hartmann A, Hofstädter F, Wieland WF, Eder F: Introduction and first clinical application of a simplified immunohistochemical validation system confirms prognostic impact of KI-67 and CK20 for stage T1 urothelial bladder carcinoma: single-center analysis of eight biomarkers in a series of three hundred six patients. Clin Genitourin Cancer 2013;11:537544. 
9 Lopez-Beltran A, Luque RJ, Alvarez-Kindelan J, Quintero A, Merlo F, Carrasco JC, Requena MJ, Montironi R: Prognostic factors in stage T1 grade 3 bladder cancer survival: the role of G1-S modulators (p53, p21Waf1, p27kip1, Cyclin D1, and Cyclin D3) and proliferation index (ki67-MIB1). Eur Urol 2004;45:606-612.

10 Cancer Genome Atlas Research Network: Comprehensive molecular characterization of urothelial bladder carcinoma. Nature 2014; 507:315-322.

11 Choi W, Porten S, Kim S, Willis D, Plimack ER, Hoffman-Censits J, Roth B, Cheng T, Tran M, Lee IL, Melquist J, Bondaruk J, Majewski T, Zhang S, Pretzsch S, Baggerly K, Siefker-Radtke A, Czerniak B, Dinney CP, McConkey DJ: Identification of distinct basal and luminal subtypes of muscle-invasive bladder cancer with different sensitivities to frontline chemotherapy. Cancer Cell 2014;25: 152-165.

12 Sjödahl G, Lauss M, Lövgren K, Chebil G, Gudjonsson S, Veerla S, Patschan O, Aine M, Fernö M, Ringnér M, Månsson W, Liedberg F, Lindgren D, Höglund M: A molecular taxonomy for urothelial carcinoma. Clin Cancer Res 2012;18:3377-3386.

13 Losa A, Hurle R, Lembo A: Low dose bacillus Calmette-Guerin for carcinoma in situ of the bladder: long-term results. J Urol 2000;163: 68-71; discussion 71-72.

14 Guiu S, Michiels S, André F, et al: Molecular subclasses of breast cancer: how do we define them? The IMPAKT 2012 Working Group Statement. Ann Oncol 2012;23:2997-3006.

15 Shokouh TZ, Ezatollah A, Barand P: Interrelationships between Ki67, HER2/neu, p53, ER, and PR status and their associations with tumor grade and lymph node involvement in breast carcinoma subtypes: Retrospective-
Observational Analytical Study. Medicine (Baltimore) 2015;94:e1359.

16 Rodríguez-Alonso A, Pita-Fernández S, González-Carreró J, Nogueira-March JL: p53 and ki67 expression as prognostic factors for cancer-related survival in stage T1 transitional cell bladder carcinoma. Eur Urol 2002;41: 182-188; discussion 188-189.

17 Ding W, Gou Y, Sun C, Xia G, Wang H, Chen Z, Tan J, Xu K, Qiang D: Ki-67 is an independent indicator in non-muscle invasive bladder cancer (NMIBC); combination of EORTC risk scores and Ki-67 expression could improve the risk stratification of NMIBC. Urol Oncol 2014;32:42.e13-e19.

18 Gunia S, Koch S, Hakenberg OW, May M, Kakies C, Erbersdobler A: Different HER2 protein expression profiles aid in the histologic differential diagnosis between urothelial carcinoma in situ (CIS) and non-CIS conditions (dysplasia and reactive atypia) of the urinary bladder mucosa. Am J Clin Pathol 2011; 136:881-888

19 Chen PC, Yu HJ, Chang YH, Pan CC: Her2 amplification distinguishes a subset of non-muscle-invasive bladder cancers with a high risk of progression. J Clin Pathol 2013;66:113-119.

20 Iyer G, Al-Ahmadie $\mathrm{H}$, Schultz $\mathrm{N}$, Hanrahan AJ, Ostrovnaya I, Balar AV, Kim PH, Lin O, Weinhold N, Sander C, Zabor EC, Janakiraman M, Garcia-Grossman IR, Heguy A, Viale A, Bochner BH, Reuter VE, Bajorin DF, Milowsky MI, Taylor BS, Solit DB: Prevalence and co-occurrence of actionable genomic alterations in high-grade bladder cancer. J Clin Oncol 2013;31:3133-3140.

21 de Pinieux G, Colin D, Vincent-Salomon A, Couturier J, Amsellem-Ouazana D, Beuzeboc $\mathrm{P}$, Vieillefond A: Confrontation of immunohistochemistry and fluorescent in situ hy- bridization for the assessment of HER-2/neu (c-erbb-2) status in urothelial carcinoma. Virchows Arch 2004;444:415-419.

22 Bongiovanni L, Arena V, Vecchio FM, Racioppi M, Bassi P, Pierconti F: HER-2 immunohistochemical expression as prognostic marker in high-grade T1 bladder cancer (T1G3). Arch Ital Urol Androl 2013;85:7377.

23 Hayashi T, Seiler R, Oo HZ, Jäger W, Moskalev I, Awrey S, Dejima T, Todenhöfer T, Li N, Fazli L, Matsubara A, Black PC: Targeting HER2 with T-DM1, an antibody cytotoxic drug conjugate, is effective in HER2 over expressing bladder cancer. J Urol 2015;194: 1120-1131.

24 Grivas PD, Day KC, Karatsinides A, Paul A, Shakir N, Owainati I, Liebert M, Kunju LP, Thomas D, Hussain M, Day ML: Evaluation of the antitumor activity of dacomitinib in models of human bladder cancer. Mol Med 2013;19:367-376

25 Hussain MH, MacVicar GR, Petrylak DP, Dunn RL, Vaishampayan U, Lara PN Jr, Chatta GS, Nanus DM, Glode LM, Trump DL, Chen H, Smith DC; National Cancer Institute: Trastuzumab, paclitaxel, carboplatin, and gemcitabine in advanced human epidermal growth factor receptor-2/neu-positive urothelial carcinoma: results of a multicenter phase II National Cancer Institute trial. J Clin Oncol 2007;25:2218-2224.

26 Wezel F, Erben P, Gaiser T, Budjan J, von Hardenberg J, Michel MS, Bolenz C: Complete and durable remission of human epidermal growth factor receptor 2-positive metastatic urothelial carcinoma following thirdline treatment with trastuzumab and gemcitabine. Urol Int 2016, Epub ahead of print. 